\title{
Experimental Study on the Vibration Control Effect of Long Elastic Sleeper Track in Subways
}

\author{
Xiaopei Cai ${ }^{D},{ }^{1}$ Dacheng Li, ${ }^{1}$ Yanrong Zhang, ${ }^{1,2}$ Qian Miao, ${ }^{1}$ and Rixin Cui ${ }^{1}$ \\ ${ }^{1}$ School of Civil Engineering, Beijing Jiaotong University, Beijing 100044, China \\ ${ }^{2}$ State Key Laboratory of Silicate Materials for Architectures (Wuhan University of Technology), Wuhan 430070, China \\ Correspondence should be addressed to Xiaopei Cai; xpcai@bjtu.edu.cn
}

Received 17 February 2018; Accepted 1 April 2018; Published 14 May 2018

Academic Editor: Sergio De Rosa

Copyright ( 2018 Xiaopei Cai et al. This is an open access article distributed under the Creative Commons Attribution License, which permits unrestricted use, distribution, and reproduction in any medium, provided the original work is properly cited.

\begin{abstract}
The vibration effect of urban rail transit has gained attention from both academia and the industry sector. Long Elastic Sleeper Track (LEST) is a new structure for vibration reduction which has recently been designed and applied to Chinese subways. However, little research has been devoted to its vibration reduction effect. In this study, field tests were conducted during peak transit hours on Beijing Subway Line 15 to examine the vibration reduction effects of the common ballastless track and LEST on both straight and curved sections. The results demonstrate that although LEST increases the wheel-rail vertical forces, rail vertical displacements, and rail accelerations to some extent, these effects do not threaten subway operational safety, and vibrations of track bed and tunnel wall are positively mitigated. LEST has an obvious vibration reduction effect at frequencies above $40 \mathrm{~Hz}$. In straight track, the vibration of bottom of the tunnel wall measured in one-third octave bands is reduced by $10.52 \mathrm{~dB}$, while the vibration at point on the tunnel wall at $1.5 \mathrm{~m}$ height is reduced by $9.60 \mathrm{~dB}$. For the curved track, the vibrations at those two points are reduced by $9.35 \mathrm{~dB}$ and $8.44 \mathrm{~dB}$, respectively. This indicates that LEST reduces vibrations slightly more for the straight track than for the curved track.
\end{abstract}

\section{Introduction}

Urban rail transit has alleviated the great traffic pressure induced by accelerated urbanization [1]. The vibrations caused by train operation are transmitted from the rail to the track bed, tunnel wall, and surrounding rock. This influences the surrounding environment [2], especially in vibration-sensitive areas such as hospitals, schools, precision instrument laboratories, residential buildings, and ancient buildings [3].

Research is actively ongoing worldwide to decrease the effects of vibration caused by subway operation, and various measures have been applied to the construction of subway lines. Hui and $\mathrm{Ng}[4]$ measured in situ rail viaduct vibrations and demonstrated that concrete floating slab track can reduce the vibration level by more than $30 \mathrm{~dB}$ within a frequency range of 63-200 Hz. Miwa et al. [5], Kim and Youn [6], and Hussein and Hunt [7] also found that the floating slab track can effectively reduce the vibration caused by train. Costa et al. [8] put forward that placing a ballast mat beneath the subballast can considerably reduce the free-field vibrations at frequencies above $40 \mathrm{~Hz}$ by up to $20 \mathrm{~dB}$. Similarly, Xin and Gao [9] and $\mathrm{Xu}$ et al. [10] concluded that a mat slab layered under the track can reduce vibrations within bridges and tunnels. Xia et al. [11] established a numerical model representing the train-track-viaduct system and studied the dynamic responses of an elevated bridge with the ladder sleeper track. Their results showed that the ladder sleeper track also has a very good vibration mitigation effect. Many other vibration reduction measures have been also applied in China and abroad, such as high-resilience fastening systems [12], labyrinth constrained damped rails [13], sleeper cushions [14], shock absorber fasteners [15], and the floating ladder sleeper track [16].

The Long Elastic Sleeper Track (LEST) is a new type of vibration reduction track based on the Low Vibration Track (LVT). It has gradually been applied to urban rail transit in recent years because it is economical and overcomes the defects of LVT with an obvious advantage in terms of medium vibration reduction demands. Furthermore, LEST enhances 


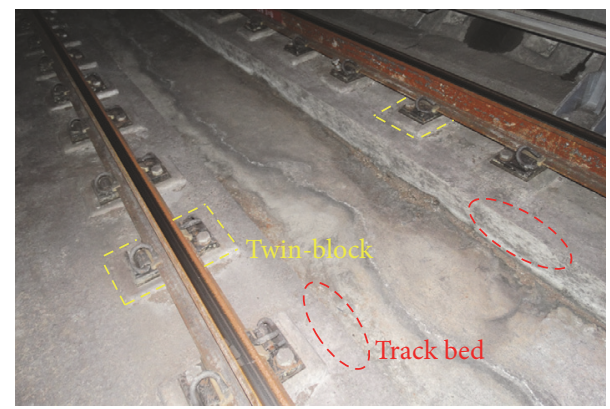

(a) Common ballastless track

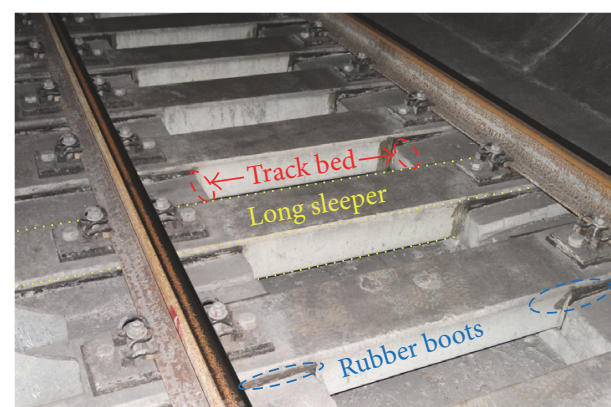

(b) LEST

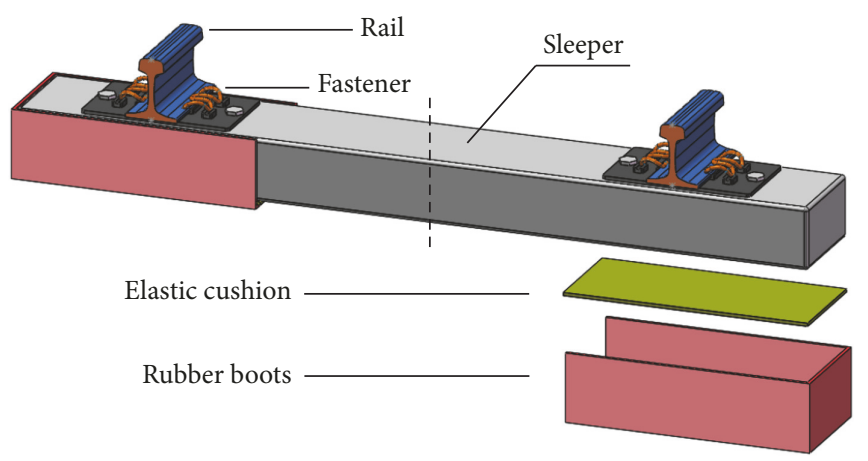

(c) Schematic of the LEST structure

FIGURE 1: Track structures of dynamic tests.

the integrity of the track structure and improves the stability of the track panel. LEST places the drainage ditch in the center of the track bed so that water within the boots can be easily drained away. For these reasons, LEST has been applied to subway lines such as Beijing Subway Airport Express, Beijing Subway Line 9, Beijing Subway Line 15, and Shanghai Subway Line 7. To study the dynamic performance of LEST, Zeng et al. [17] analyzed the damping effect of LEST by performing wheel load drop tests on Beijing Subway Airport Express. Fan [18] established a calculation model for the LEST structure and simulated the whole process of the wheel load drop tests; the vibration characteristics of the track were analyzed for proposing the reasonable stiffness range under the rail. Using the vehicle-track coupling theory and Hamilton principle, Wu and Liu [19] presented a theoretical analysis on the laws governing the track dynamic stiffness, train speed, fastener stiffness, and elastic cushion stiffness of LEST. However, up to now, all the published research on LEST was based solely on theoretical analysis. Few experimental studies have been conducted on LEST, and investigations about dynamic testing for installed LEST are limited.

In order to make up for the gap in dynamic test research on LEST, field tests were conducted on Beijing Subway Line 15 to analyze the dynamic characteristics of LEST in subway tunnel and quantify its vibration reduction effects. The vibration reduction effects of LEST for both straight and curved tracks were compared and analyzed to generate concrete data for application and design optimization.

\section{LEST Structure and Dynamic Tests}

2.1. LEST Structure. LEST is composed of rails, a fastening system, and a long sleeper, as shown in Figure 1. LEST employs long concrete sleepers with 2,300 mm length, $300 \mathrm{~mm}$ width, and 170-182.5 mm height. Both ends of the track are wrapped with rubber boots. The elastic cushions composed of ethylene-propylene-diene monomer (EPDM) microcellular rubber, which provides the damping effect, are used between the sleepers and boots. The common ballastless track is the twin-block structure which is constructed as an integrity and consists of the concrete short sleepers and track bed.

In theoretical analysis of the vibration reduction characteristics of LEST, the sleeper, rail, and fastening system above the elastic cushion are regarded as mass blocks, and the elastic cushion is simulated by a spring-damping element, as shown in Figure 2. When a harmonic exciting force with the frequency of $\omega$ acts on the mass blocks, it is assumed that the counterforce acting on the foundation through the spring and damper is given by $F=F_{0} \sin \omega t$. The differential equation of motion for the system is

$$
m \ddot{x}+c \dot{x}+k x=F_{0} \sin \omega t,
$$

where $m$ is the system mass, $c$ is the spring damping, and $k$ is the spring stiffness. By solving (1), the steady-state vibration response of the system is obtained:

$$
x=\frac{F_{0}}{\sqrt{\left(1-v^{2}\right)^{2}+(2 \xi v)^{2}}},
$$


TABLE 1: Profile of test positions in Beijing Subway Line 15.

\begin{tabular}{lcccc}
\hline Test positions & $\begin{array}{c}\text { Liudaokou-Beishatan } \\
\text { (right line) }\end{array}$ & $\begin{array}{c}\text { Liudaokou-Beishatan } \\
\text { (left line) }\end{array}$ & $\begin{array}{c}\text { Guanzhuang- } \\
\text { Wangjing West } \\
\text { (right line) }\end{array}$ & $\begin{array}{c}\text { Wangjing } \\
\text { West-Wangjing } \\
\text { (left line) }\end{array}$ \\
\hline Track type & LEST & $\begin{array}{c}\text { Common ballastless } \\
\text { track }\end{array}$ & $\begin{array}{c}\text { LEST } \\
\text { ballastless track } \\
\text { Line type }\end{array}$ \\
Average train speed $\left(\mathrm{km} \cdot \mathrm{h}^{-1}\right)$ & Straight & Straight & $(R=350 \mathrm{~m})$ & $(R=350 \mathrm{~m})$ \\
Tunnel depth $(\mathrm{m})$ & 76.5 & 71.8 & 56.6 & 27.5 \\
\hline
\end{tabular}

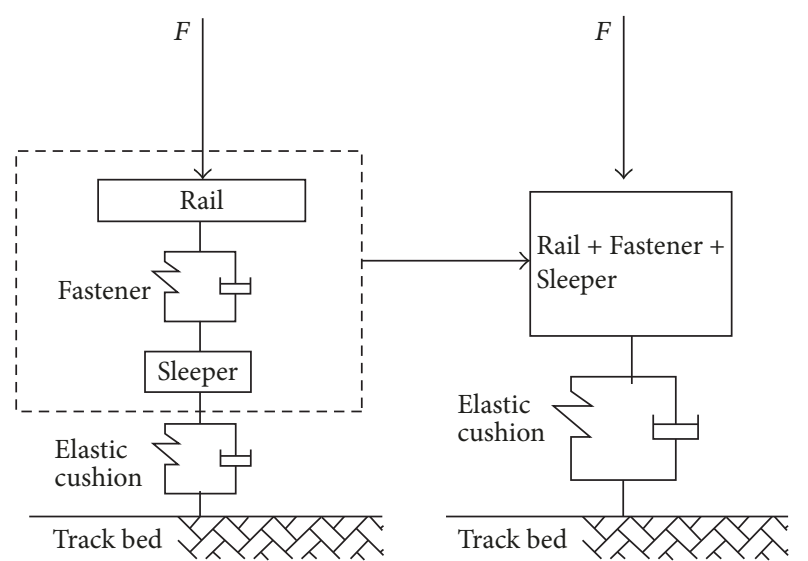

FIGURE 2: Mass-spring-damper system of LEST structure.

where $v=\omega / \omega_{n}$ is the frequency ratio (i.e., ratio of the excitation frequency to the natural frequency of the system) and $\xi=c / 2 \omega_{n} m$ is the system damping ratio. The resultant force transferred from mass blocks to the ballast bed is the resultant force of the elastic force $k x$ and damping force $c \dot{x}$. This is represented by $F_{R}$ :

$$
F_{R}=\frac{F_{0} \sqrt{1+(2 \xi v)^{2}}}{\sqrt{\left(1-v^{2}\right)^{2}+(2 \xi v)^{2}}} .
$$

According to the previous definition, the force transfer ratio of this system is [20]

$$
\lambda_{F}=\frac{\sqrt{1+(2 \xi v)^{2}}}{\sqrt{\left(1-v^{2}\right)^{2}+(2 \xi v)^{2}}} .
$$

If $\lambda_{F}>1$, the damping measures have a damping effect; if $\lambda_{F}<1$, the damping measures do not have a damping effect.

When $w / w_{n}$ is approximately 1 , the vibration transmission coefficient can be represented as $\lambda_{F}=\sqrt{1+(1 / 2 \xi)^{2}}$. In the resonant region, $\xi$ increases with $C_{b}$, which greatly reduces vibration transmission coefficient. Thus, theoretical analysis demonstrates that the application of LEST has a vibration reduction effect, which needs to be quantified through field tests.
2.2. Track Dynamic Tests. Both common ballastless track and LEST along Beijing Subway Line 15 were tested under similar conditions to evaluate the vibration reduction effects in both straight and curved tracks.

The design speed of Beijing Subway Line 15 is $80 \mathrm{~km} / \mathrm{h}$, and six marshalling type B DKZ31 trains run on this line, with a wheelbase of $2,300 \mathrm{~mm}$ and axle load of $140 \mathrm{kN}$. The tunnel diameter is $5.8 \mathrm{~m}$, and the space between fasteners is $595 \mathrm{~mm}$.

Figure 3 shows the common ballastless track and LEST at the test sites and the test sections distributed along Beijing Subway Line 15. In total, four test sections were selected: two straight and two curved sections. As given in Table 1, the left and right lines between Liudaokou-Beishatan stations were tested. Two curved sections of track with an identical radius of $350 \mathrm{~m}$ were measured between Guanzhuang-Wangjing West stations and between Wangjing West-Wangjing stations.

Figure 4 shows the distribution plane for the measuring points in each section. The vibration and track dynamic characteristics were tested, including the vertical vibration accelerations of the rail, sleeper, track bed, and tunnel wall, the lateral and vertical wheel-rail forces, the lateral and vertical rail displacements, and the vertical displacements of the sleeper. Because of the significant difference between the buried depths of the tunnel for two sections of curved track, the ground vibration accelerations could not be compared. Therefore, the ground vibration accelerations above the straight track of the tunnel were only tested.

Figure 5 shows the layout of the vibration acceleration points of the track structure and tunnel wall. CA-YD series piezoelectric acceleration sensors (Sinocera Piezotronics, Inc.) were used in the acceleration tests. The appropriate range and sensitivity of these sensors were selected according to the location of the measuring points. For example, the range and sensitivity of rail acceleration sensor are $\pm 500 \mathrm{~g}\left(\mathrm{~g}=9.8 \mathrm{~m} / \mathrm{s}^{2}\right)$ and $1.022 \mathrm{mV} /\left(\mathrm{m} \cdot \mathrm{s}^{-2}\right)$, respectively, while those of the sleeper acceleration sensor are $\pm 10 \mathrm{~g}$ and $49.8 \mathrm{mV} /\left(\mathrm{m} \cdot \mathrm{s}^{-2}\right)$, respectively. CS series acquisition instruments (Integrated Measurement \& Control Company, Germany) were used for data acquisition. In order to collect more accurate data, the acquisition frequency of each parameter was set to $10,000 \mathrm{~Hz}$. Before the time domain analysis, a lowpass filter was used. The cut-off frequency of the low-pass filter of the rail and sleeper accelerations is $5,000 \mathrm{~Hz}$. As for the acceleration of the track bed, tunnel wall, and ground, the wheel-rail forces, and the dynamic displacements of rail 


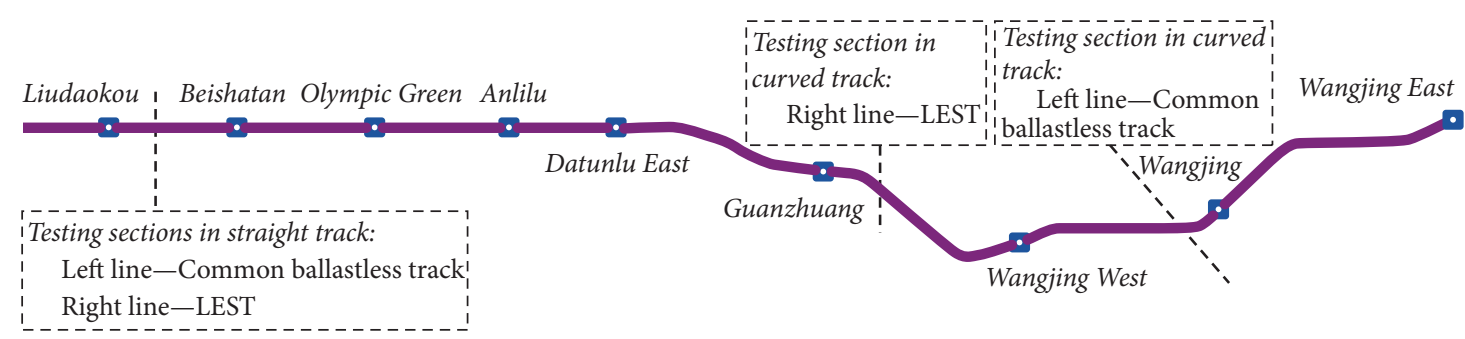

FIgURE 3: Distribution of test sections along Beijing Subway Line 15.
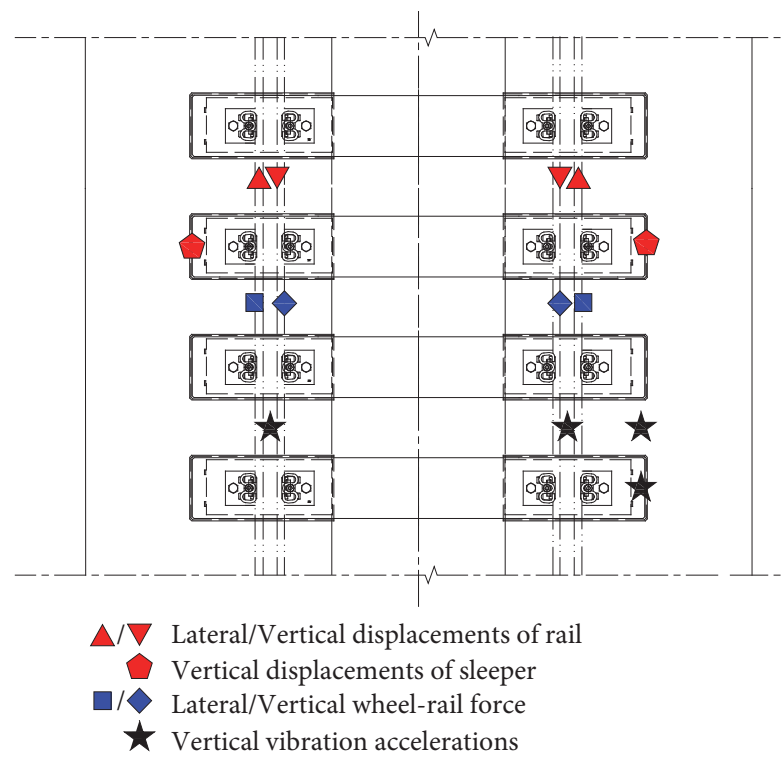

FIGURE 4: Arrangement plan of measurement points.

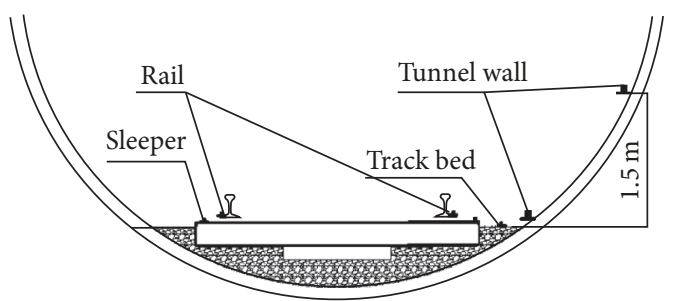

FIGURE 5: Arrangement of acceleration measuring points in the tunnel.

and sleeper, the cut-off frequency is $500 \mathrm{~Hz}$. Multichannel combined automatic trigger acquisition was used as the data acquisition mode. As for the wheel-rail force calibration, a hydraulic jack and reaction frame were used to determine the relationship between the wheel-rail force and rail strain. Figure 6 shows the field installation of sensors for measuring the wheel-rail lateral and vertical forces, dynamic displacements, and accelerations. The wheel-rail force calibration method and device that are shown in Figure 6(f) strictly follow the Chinese code Track Side Test Methods of Vertical and Lateral Wheel-Rail Forces (TB/T 2489-2016).
The effects of the vibration control measures were analyzed according to the Measurement Method of Environmental Vibration of Urban Area (GB/T 13441-2007). The $Z$ vibration level insertion loss in the frequency range of $1-200 \mathrm{~Hz}$ is used to evaluate the vibration reduction effects [21]. The insertion loss is the difference between the vibration levels with and without vibration control measures, which is defined as

$$
L_{1}=20 \lg \frac{a_{2 R}}{a_{2}},
$$

where $a_{2 R}$ is the vibration response of common ballastless track and $a_{2}$ is the vibration response with LEST. If $L_{1} \geq 0$, it indicates that there is a vibration reduction effect.

By adding the base acceleration $a_{0}=10^{-6} \mathrm{~m} \cdot \mathrm{s}^{-2}$, the insertion loss can be calculated as follows:

$$
\begin{aligned}
L_{1} & =20 \lg \frac{a_{2 R}}{a_{2}}=20 \lg \left(\frac{a_{2 R}}{a_{0}} \cdot \frac{a_{0}}{a_{2}}\right) \\
& =20 \lg \frac{a_{2 R}}{a_{0}}-20 \lg \frac{a_{2}}{a_{0}}, \\
L_{1} & =V L_{2 R}-V L_{2} .
\end{aligned}
$$

To evaluate the vibration reduction effect of LEST, (7) is used to calculate the insertion loss at tunnel wall and ground with common ballastless track and LEST.

\section{Experimental Results of Wheel-Rail Forces and Dynamic Displacements}

3.1. Analysis of the Wheel-Rail Forces. The derailment coefficient and wheel unloading rate, which are obtained from the measured dynamic wheel-rail forces, are two important indicators for evaluating the safety of subway trains. The derailment coefficient refers to the ratio of the wheel-rail lateral force $L$ to the wheel-rail vertical force $V$ at a certain moment. The wheel unloading rate is defined as the ratio of the wheel load shedding $\Delta V$ to the average static wheel weight $\bar{V}$ at a given time. In the tests, both the lateral and vertical wheel-rail forces were measured at four cross sections. Figure 7 shows the time-history curves for the vertical and lateral wheel-rail force in straight track of common ballastless track.

According to the statistics of 400 groups of preferable data during peak operation periods, the average vertical wheelrail forces on the left and right rails of the straight common 


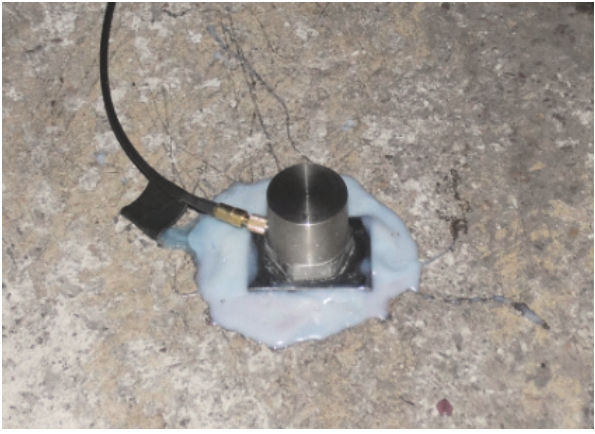

(a)

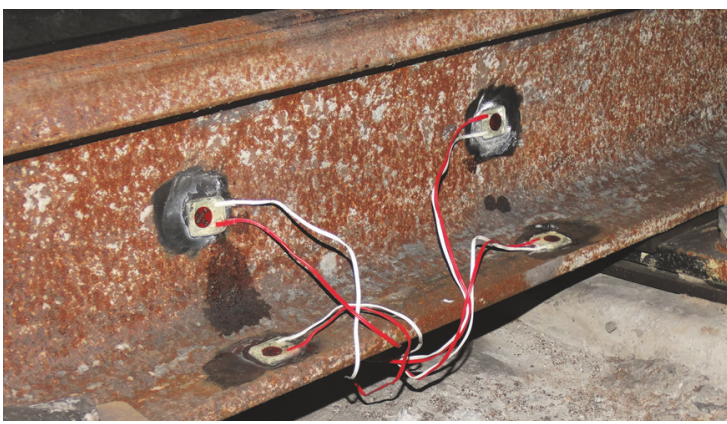

(c)

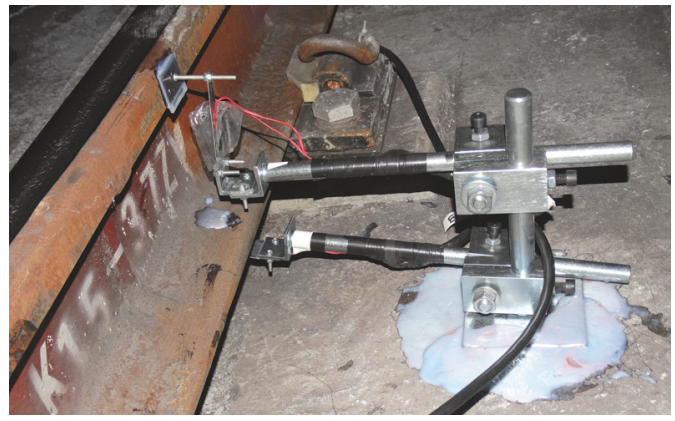

(e)

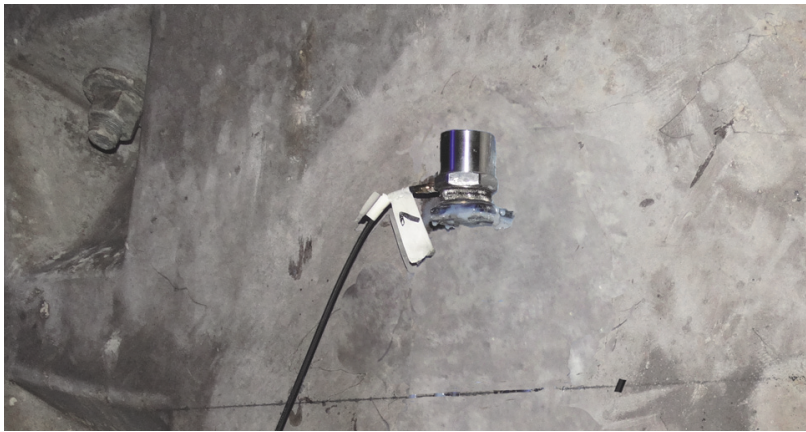

(b)

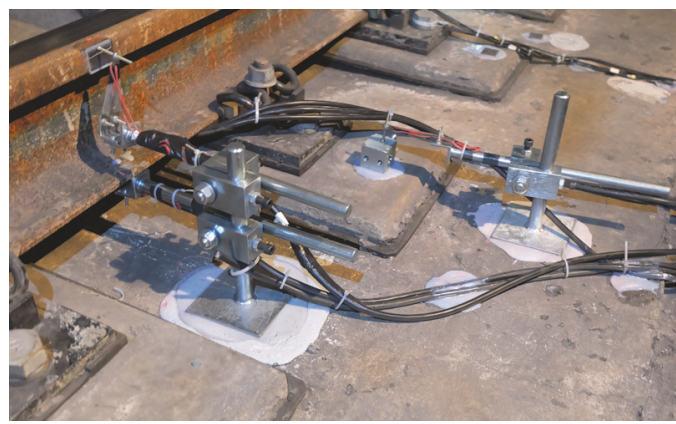

(d)

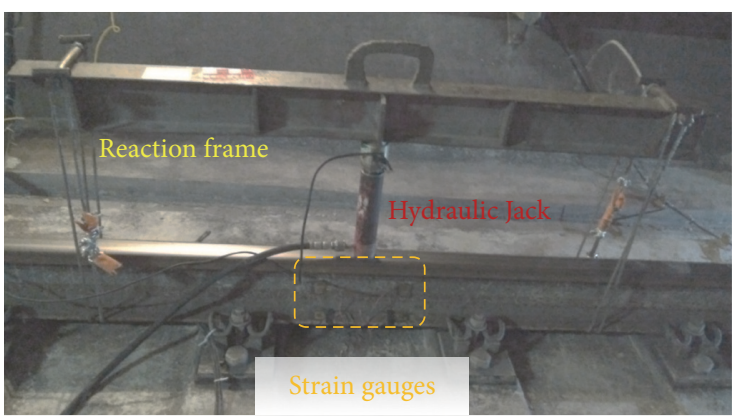

(f)

FIGURE 6: Field installation of sensors and calibration. (a) Acceleration sensor of track bed; (b) acceleration sensor of tunnel wall; (c) wheelrail force strain gauges; (d) test device for vertical displacements of the rail and sleeper in LEST; (e) test device for vertical displacements of the rail in common ballastless track; (f) vertical wheel-rail force calibration.

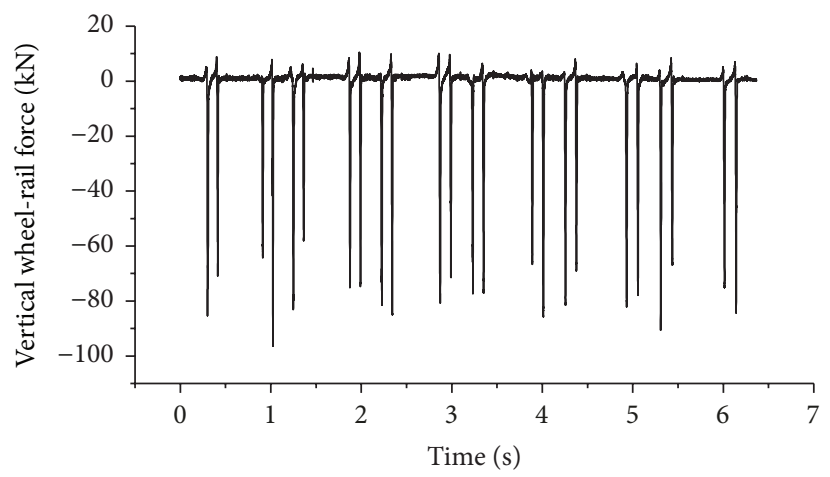

(a) Vertical wheel-rail forces

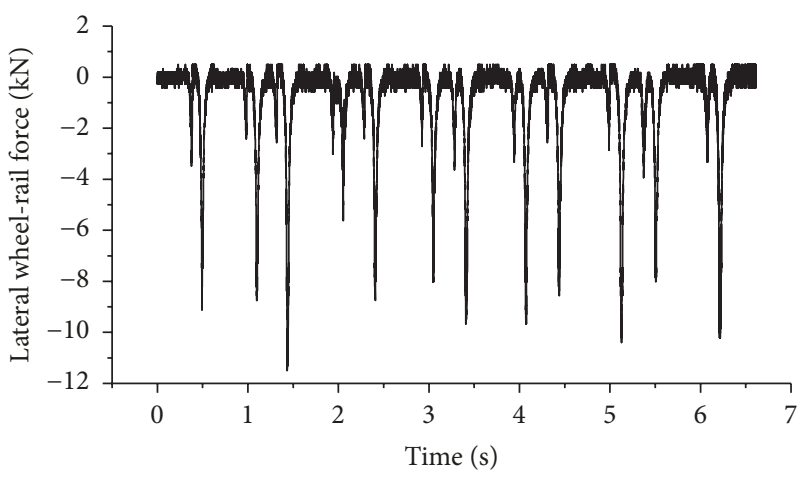

(b) Lateral wheel-rail forces

FIGURE 7: Time-history curves of wheel-rail forces for straight common ballastless track. 
TABLE 2: Statistics of train safety indices.

\begin{tabular}{lcc}
\hline Safety index & Derailment coefficient & Wheel unloading rate \\
\hline Common ballastless track (straight) & & 0.15 \\
$\quad$ Left rail & 0.14 & 0.22 \\
Right rail & & 0.12 \\
LEST (straight) & 0.11 & 0.19 \\
$\quad$ Left rail & & 0.31 \\
$\quad$ Right rail & 0.29 \\
Common ballastless track (curved) & 0.16 \\
$\quad$ Inner rail & 0.21 & 0.28 \\
Outer rail & 0.14 \\
LEST (curved) & & \\
Inner rail & & \\
Outer rail & & \\
\hline
\end{tabular}

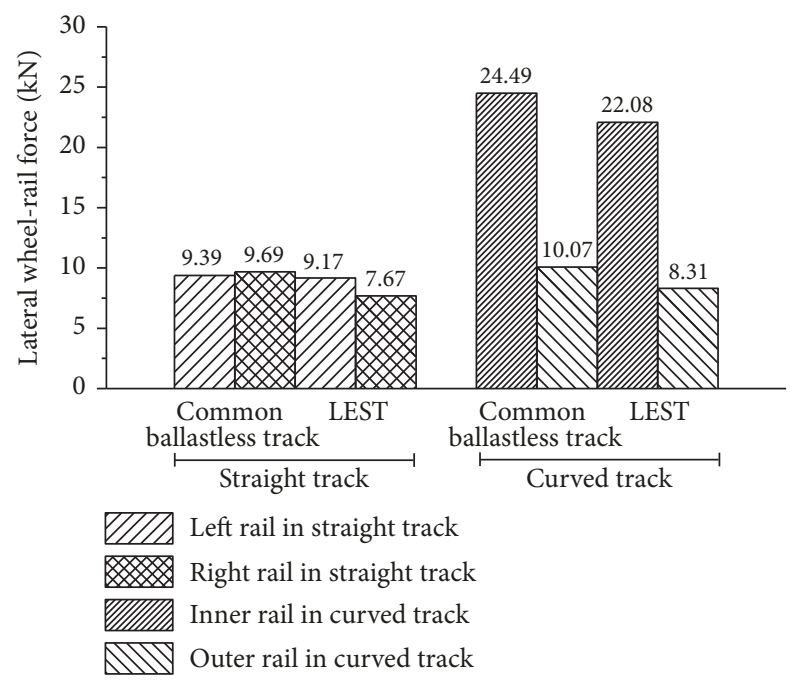

(a) Mean lateral wheel-rail forces

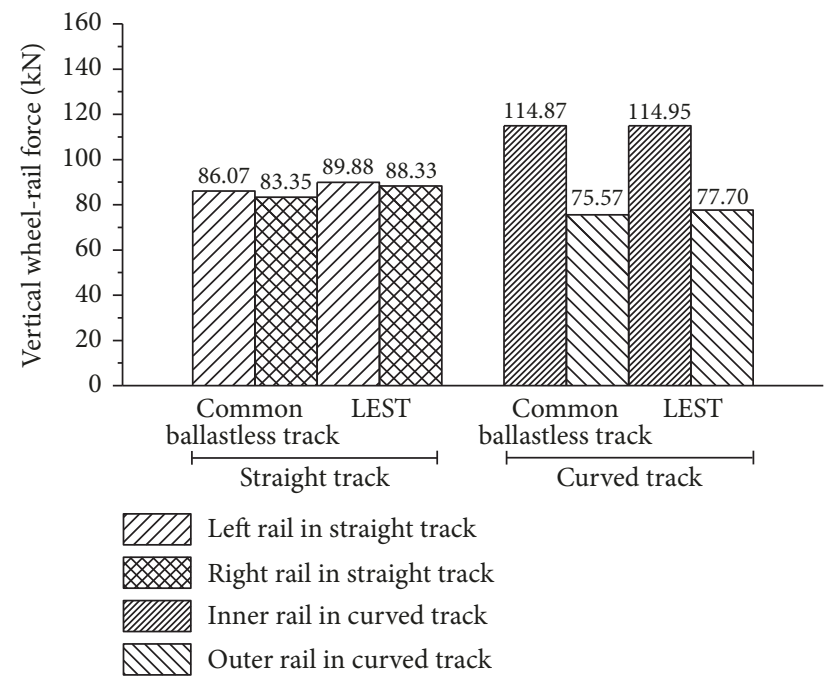

(b) Mean vertical wheel-rail forces

FIGURE 8: Wheel-rail forces for all the test positions.

ballastless track were $86.07 \mathrm{kN}$ and $83.35 \mathrm{kN}$, respectively. The lateral wheel-rail forces were $9.39 \mathrm{kN}$ and $9.69 \mathrm{kN}$, respectively. Figure 8 shows further wheel-rail forces statistics gathered from other cross sections. With LEST, the vertical wheel-rail forces slightly increased by $2.82 \%-5.96 \%$ because of the deformation of the elastic cushion under the dynamic load. However, this deformation has little influence on the lateral wheel-rail forces. The wheel-rail forces are mainly determined by track irregularity, and hence the presence of elastic cushion has little effect on the forces. In curved track, the vertical wheel-rail forces of the inner rail are larger owing to a surplus superelevation on the outer rail.

Table 2 presents the maximum derailment coefficient and wheel unloading rate of the four test cross sections. The maximum derailment coefficient is 0.29 , which is far less than the prescribed limit of 1.00 . The maximum wheel unloading rate is 0.31 , which is less than the prescribed limit of 0.60 .
Therefore, laying LEST does not affect the operational safety of subway.

3.2. Analysis of the Structural Dynamic Displacements. The lateral and vertical displacements of rail and vertical displacements of sleeper were also measured. Figure 9 shows the typical time-history curve of the straight track with LEST. Figure 10 shows the test results for the average lateral and vertical displacements of the rail in common ballastless track and LEST.

It can be concluded that LEST increases the vertical displacements of the rail by about $13.33 \%$ in straight track and $10.66 \%-18.48 \%$ in curved track but has little influence on the lateral rail displacements. The increase in the vertical rail displacements is because the elastic cushion of LEST experiences compressive deformation under vertical loads. The test results show that the average vertical displacements 


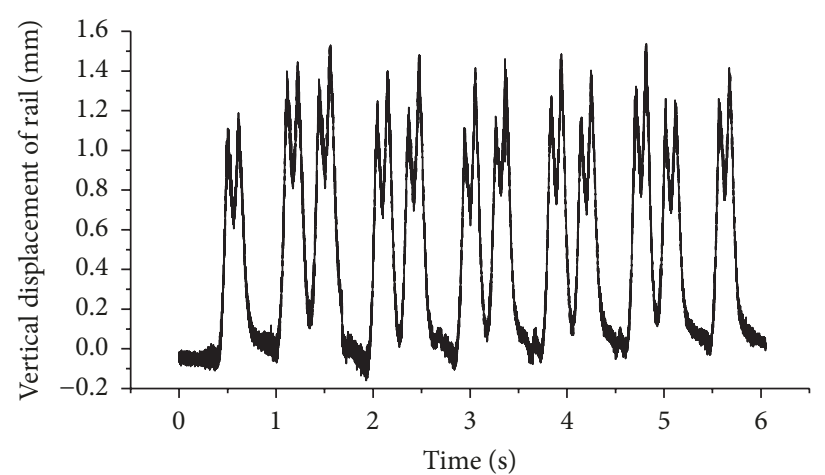

(a) Vertical displacements of rail

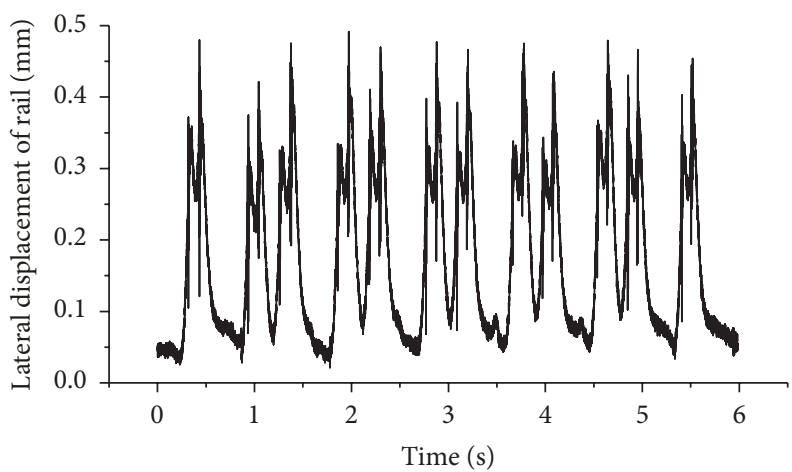

(b) Lateral displacements of rail

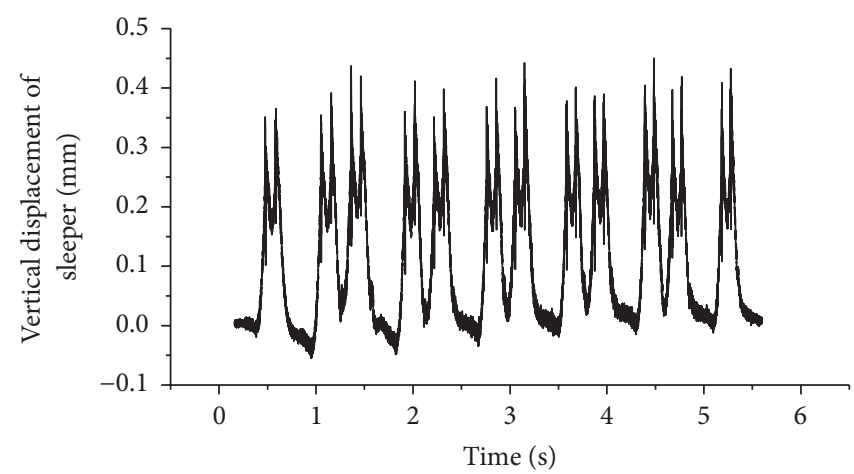

(c) Vertical displacements of sleeper

FIGURE 9: Time-history curves of the rail and sleeper for LEST in straight track.

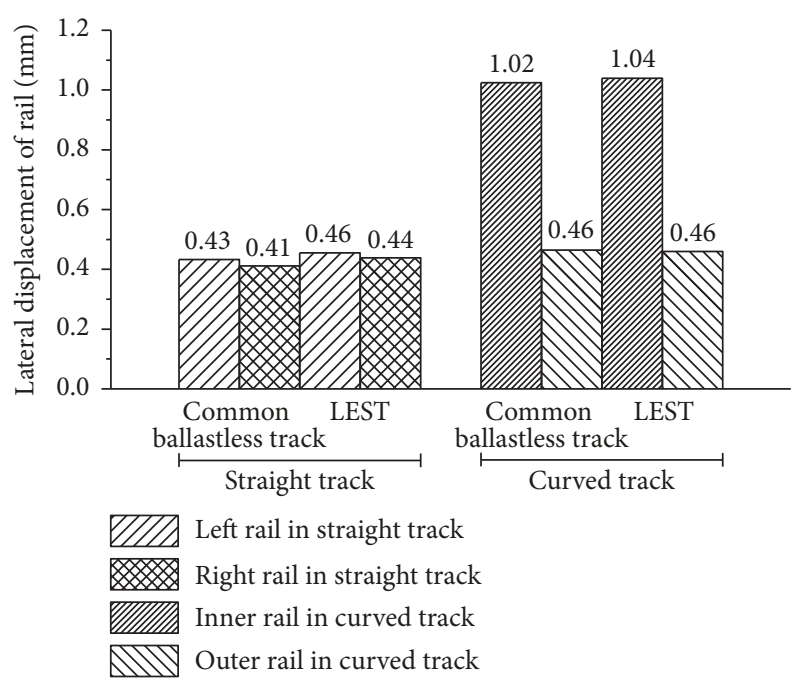

(a) Comparison of lateral rail displacements

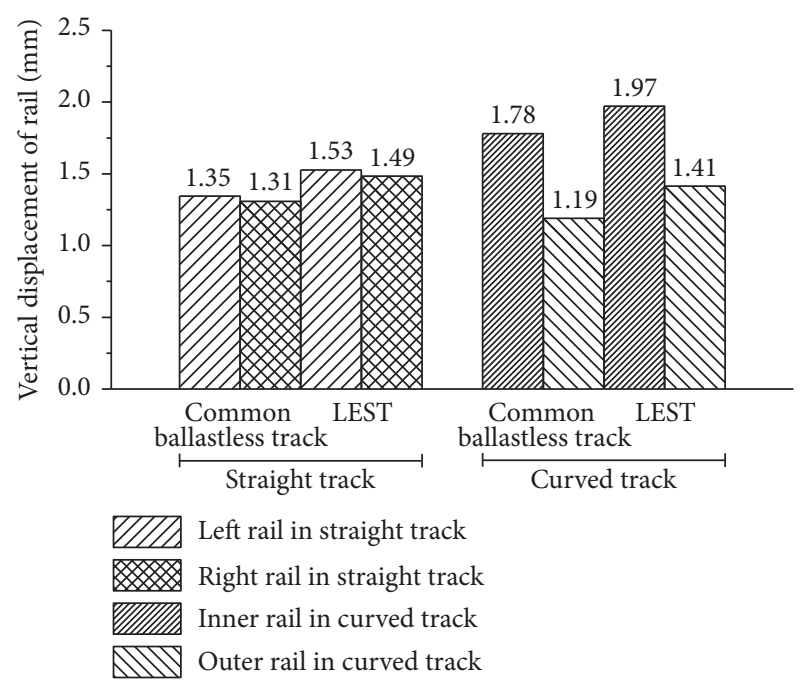

(b) Comparison of vertical rail displacements

FIGURE 10: Comparison of the average rail displacements between common ballastless track and LEST.

of the sleeper in straight track are $0.45 \mathrm{~mm}$ and $0.60 \mathrm{~mm}$ (inner rail) and $0.52 \mathrm{~mm}$ (outer rail) in curved track.

The analysis on wheel-rail forces and dynamic displacements shows that laying LEST increases the vertical wheel-rail forces and dynamic displacements, which would influence the smoothness of the railway operation. However, the evaluation of the safety index shows that LEST has little effect on the safety of the subway operation. 


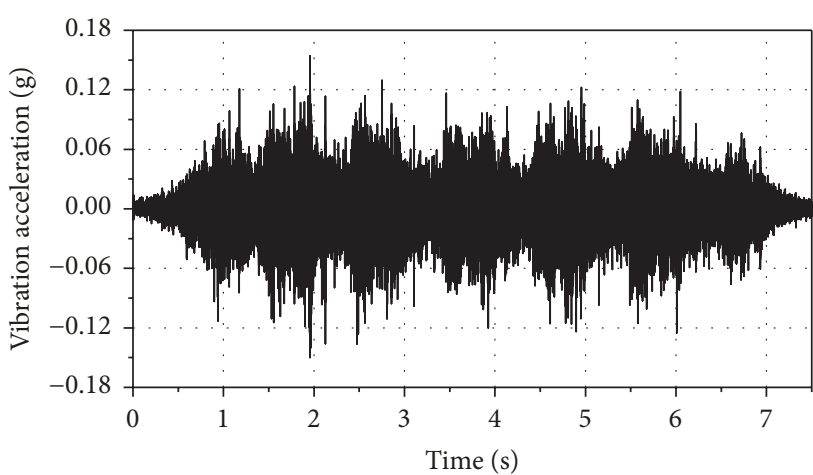

(a) Common ballastless track

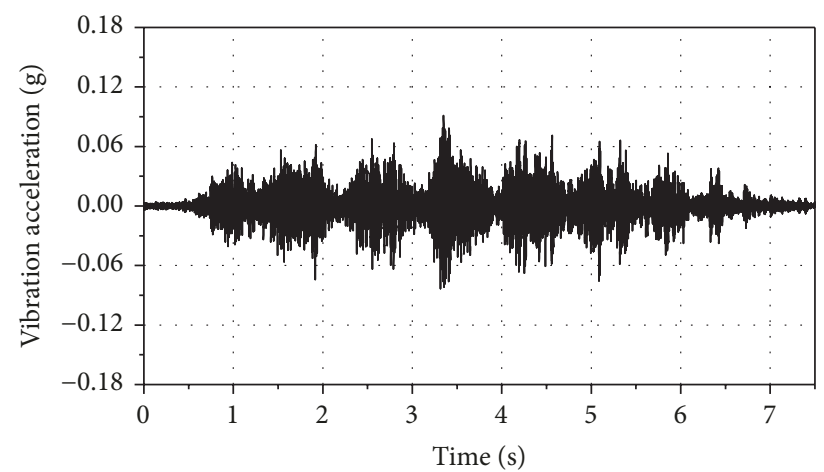

(b) LEST

FIGURE 11: Typical time-history curves of vibration accelerations of point on the tunnel wall at $1.5 \mathrm{~m}$ height in straight track.

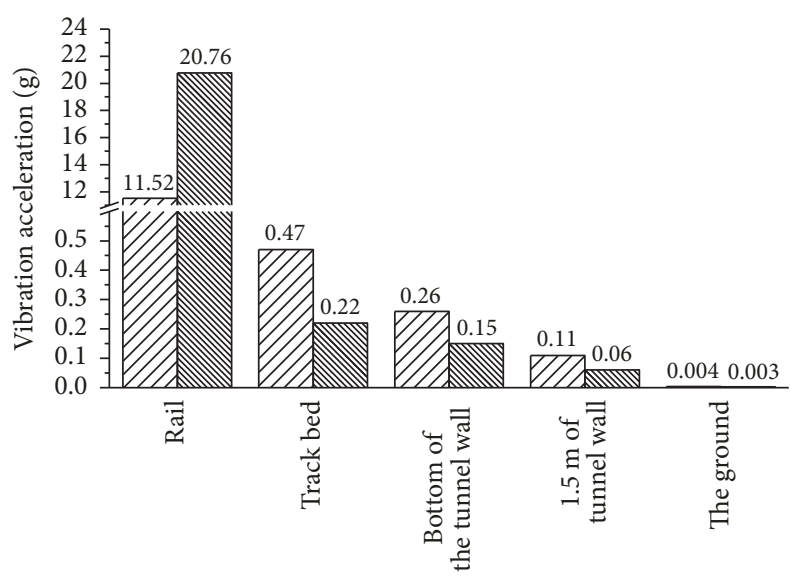

$\square Z$ Common ballastless track LEST

Figure 12: Average vibration accelerations at different measuring points in straight track.

\section{Experimental Results of Vibration Reduction}

\subsection{Analysis of Vibration Reduction in Straight Track}

4.1.1. Time Domain Analysis. Figure 11 shows the typical time-history curves of point on the tunnel wall at $1.5 \mathrm{~m}$ height. Figures 11(a) and 11(b) illustrate the accelerations of the tunnel wall with the common ballastless track and LEST, respectively. It is obvious that LEST can clearly reduce the tunnel wall vibration effectively.

Figure 12 shows the average vibration accelerations of the rail, track bed, bottom of the tunnel wall, point on the tunnel wall at $1.5 \mathrm{~m}$ height, and ground. The average rail acceleration of LEST is $20.76 \mathrm{~g}$, while that on the common ballastless track section is $11.52 \mathrm{~g}$. Obviously, LEST significantly increases the rail vibration acceleration. This is because the presence of elastic cushion reduces the restraint of the track bed to the sleeper and facilitates the free vibration of rail. Meanwhile, LEST reduces the vibration acceleration on the track bed, bottom of the tunnel wall, point on the tunnel wall at $1.5 \mathrm{~m}$ height, and ground by $52.64 \%, 44.87 \%, 44.14 \%$, and $25.0 \%$, respectively.

The time domain analysis shows that although LEST increases the vibration of the track structure above the sleeper, it also significantly reduces the vibration of the track bed, bottom of the tunnel wall, point on the tunnel wall at $1.5 \mathrm{~m}$ height, and ground.

4.1.2. Frequency Domain Analysis. The one-third octave bands spectrum of $Z$-weight was used to evaluate the vibration reduction effect in the frequency domain. The overall vibration level, which represents the degree of vibration throughout the analytical frequency range, is often used to evaluate the vibration reduction effect in the frequency domain. According to the code Mechanical Vibration and Shock-Evaluation of Human Exposure to Whole-body Vibration (ISO 2631-1-1997) [22] and Chinese code Technical Code for Floating Slab Track (CJJ/T 191-2012) [23], the overall vibration level is defined as

$$
L_{a}=10 \lg \left(\sum_{i=1}^{n} 10^{V L(i) / 10}\right),
$$

where $V L(i)$ is the vibration level of each centre frequency.

Figure 13 shows the one-third octave curve of the vertical vibration levels at bottom of the tunnel wall, point on the tunnel wall at $1.5 \mathrm{~m}$ height, and the ground. Table 3 lists the overall vibration levels of those measurement points within a frequency band of 1-200 Hz.

Figure 13 shows that LEST does not have an obvious effect on vibration reduction when the frequency is below $30 \mathrm{~Hz}$. Track vibration reduction measures are generally believed to be ineffective against vibration problems below $10-15 \mathrm{~Hz}$. These problems can only be solved by improving the performance of vehicle bogies, for example, by using low-stiffness suspension systems and resilient wheels. LEST has an obvious vibration reduction effect when the frequency is above $40 \mathrm{~Hz}$. Under these conditions, the maximum vibration reduction at bottom of the tunnel wall reaches $21.45 \mathrm{~dB}$, while vibrations at point on the tunnel wall at $1.5 \mathrm{~m}$ height and the ground are reduced by $14.56 \mathrm{~dB}$ and $9.40 \mathrm{~dB}$, respectively. The overall 
TABLE 3: Overall vibration levels of the tunnel wall and ground in straight track $(1-200 \mathrm{~Hz})(\mathrm{dB})$.

\begin{tabular}{lccc}
\hline Measuring point position & Common ballastless track & LEST & Insertion loss \\
\hline Bottom of the tunnel wall & 100.95 & 90.43 & 10.52 \\
Point on the tunnel wall at $1.5 \mathrm{~m}$ height & 79.88 & 70.28 & 9.60 \\
Ground & 71.73 & 62.89 & 8.84 \\
\hline
\end{tabular}

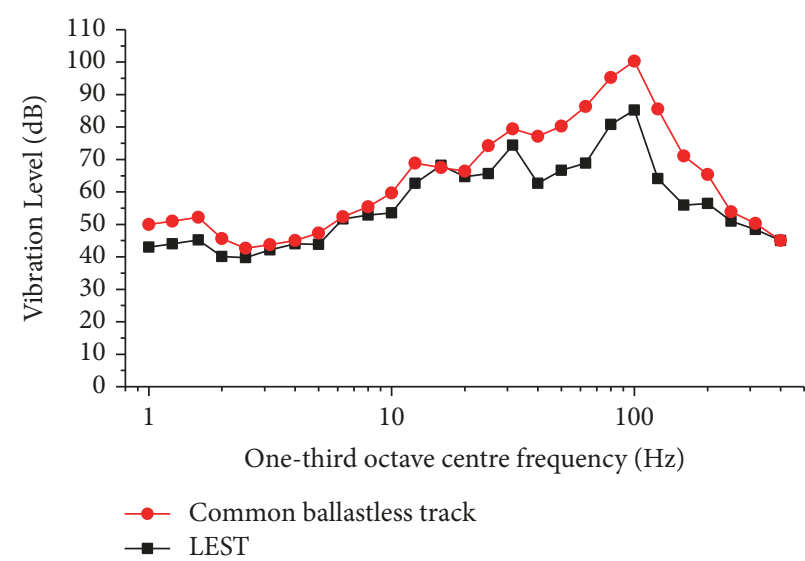

(a) Bottom of the tunnel wall

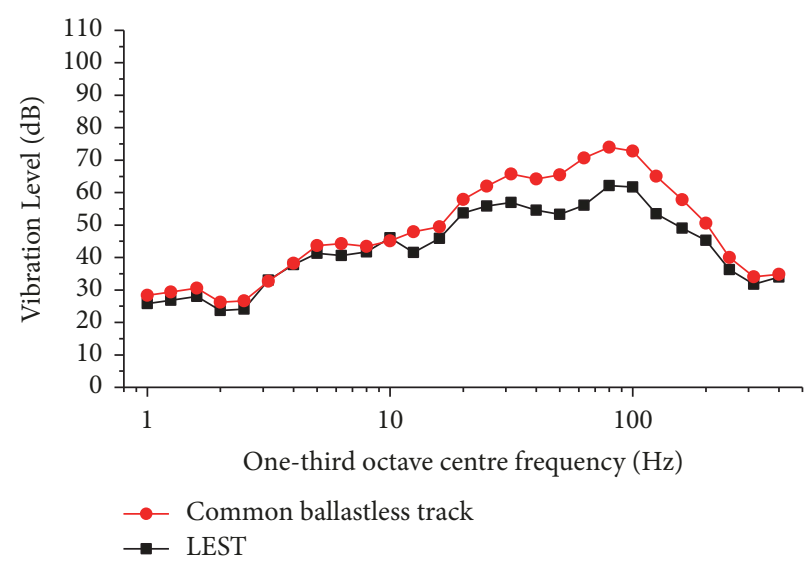

(b) Point on the tunnel wall at $1.5 \mathrm{~m}$ height

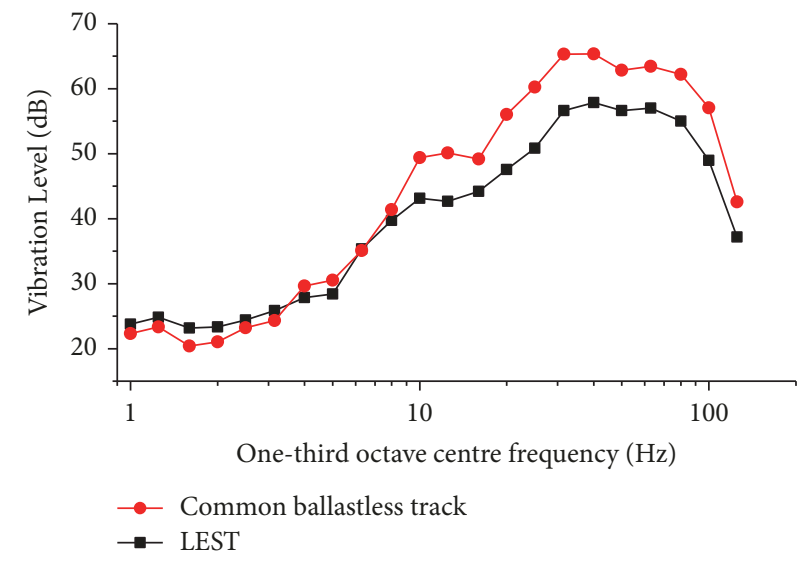

(c) Ground

FIGURE 13: One-third octave curves of the tunnel wall and ground vibration levels in straight track.

vibration levels in the one-third octave frequency range of $1-200 \mathrm{~Hz}$ are used to evaluate the average vibration reduction effect of LEST. Compared with the common ballastless track, LEST reduces the overall vibration levels at bottom of the tunnel wall, point on the tunnel wall at $1.5 \mathrm{~m}$ height, and the ground by $10.52 \mathrm{~dB}, 9.60 \mathrm{~dB}$, and $8.84 \mathrm{~dB}$, respectively. Therefore, LEST plays a positive role in vibration reduction in the frequency domain.

\subsection{Analysis of Vibration Reduction in Curved Track}

4.2.1. Time Domain Analysis. Based on the analysis of test data from the peak transit period, Figure 14 shows the typical acceleration time-history curve of point on the tunnel wall at $1.5 \mathrm{~m}$ height in curved track. Figure 15 shows the average vibration accelerations of the track bed, bottom of the tunnel wall, and point on the tunnel wall at $1.5 \mathrm{~m}$ height.

Figure 15 shows that LEST increases the vibrations of both the inner and outer rails of the curved track by $18.34 \%$ and $18.76 \%$, respectively. The vibration accelerations of the track bed, bottom of the tunnel wall, and point on the tunnel wall at $1.5 \mathrm{~m}$ height are reduced by $22.58 \%, 23.70 \%$, and $20.83 \%$, respectively. Thus, LEST can effectively reduce environmental vibration in the time domain.

4.2.2. Frequency Domain Analysis. Figure 16 shows the onethird octave curves of the vibration levels at the tunnel wall in the curved track. Within the low frequency range of $1-30 \mathrm{~Hz}$, LEST does not have an obvious vibration reduction effect, but the effect becomes noticeable when the frequency is above 
TABLE 4: Overall vibration levels of the tunnel wall in curved track $(1-200 \mathrm{~Hz})(\mathrm{dB})$.

\begin{tabular}{lccc}
\hline Measuring point position & Common ballastless track & LEST & Insertion loss \\
\hline Bottom of the tunnel wall & 88.09 & 78.74 & 9.35 \\
Point on the tunnel wall at $1.5 \mathrm{~m}$ height & 79.21 & 70.77 & 8.44 \\
\hline
\end{tabular}

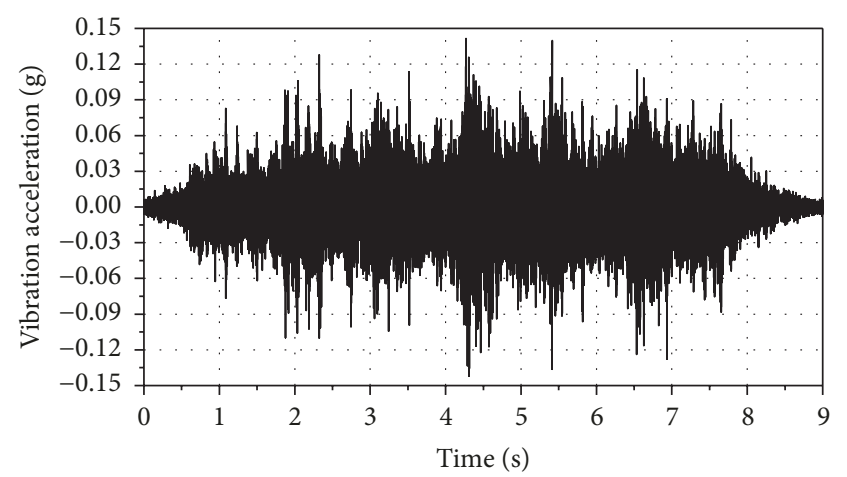

(a) Common ballastless track

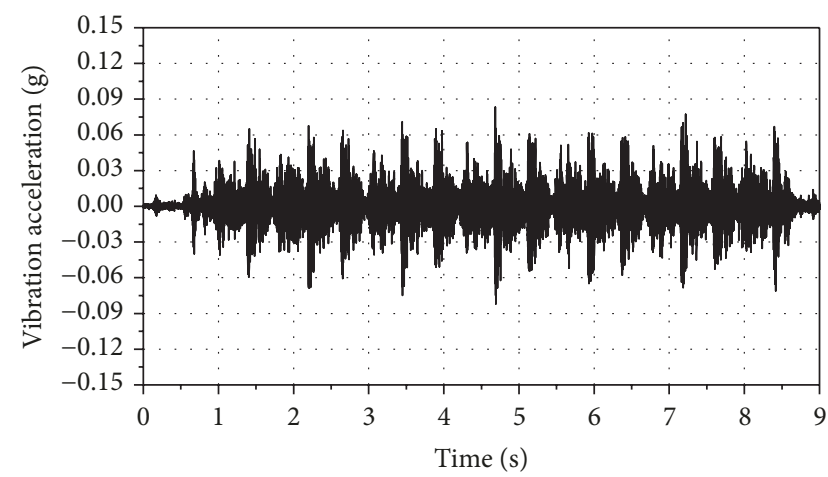

(b) LEST

FIGURE 14: Typical time-history curves of vibration accelerations of point on the tunnel wall at $1.5 \mathrm{~m}$ height in curved track.

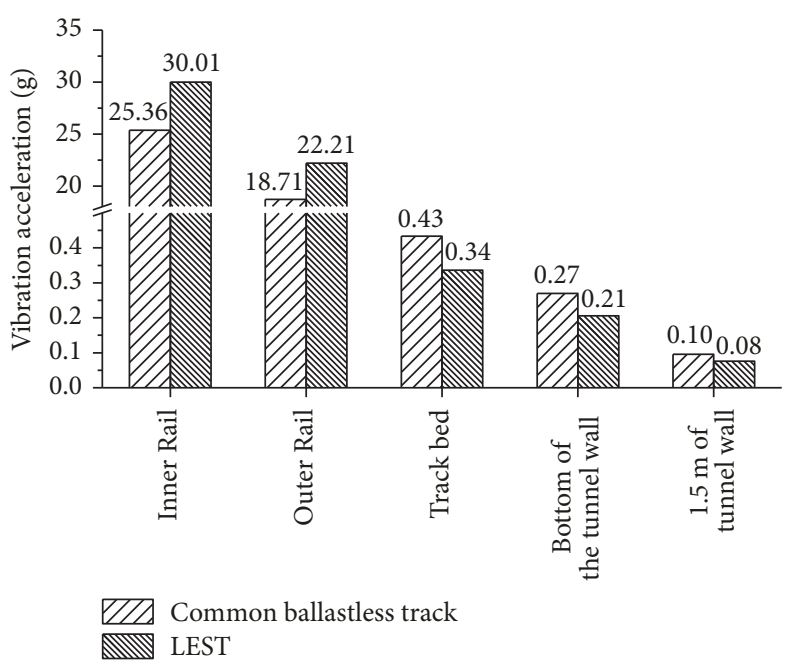

FIGURE 15: Average vibration accelerations in curved track.

$40 \mathrm{~Hz}$. The maximum vibration reductions at bottom of the tunnel wall and point on the tunnel wall at $1.5 \mathrm{~m}$ height are $22.03 \mathrm{~dB}$ and $13.82 \mathrm{~dB}$, respectively. Table 4 lists the overall vibration levels. With the laying of LEST, the vibration levels at bottom of the tunnel wall and point on the tunnel wall at $1.5 \mathrm{~m}$ height decrease by $9.35 \mathrm{~dB}$ and $8.44 \mathrm{~dB}$, respectively. Therefore, LEST has a positive vibration reduction effect in curved track.

4.3. Comparison of the Vibration Control Effects in Straight and Curved Track. A comparison of the vibration reduction effect of both common ballastless track and LEST, at each measuring point between straight and curved tracks, is shown in Figure 17. For the frequency domain, Figure 18 shows the calculated vibration insertion loss at bottom of the tunnel wall and point on the tunnel wall at $1.5 \mathrm{~m}$ height in straight and curved tracks. Figure 19 compares the overall vibration level reductions.

For the time domain, Figure 17 shows that LEST has a greater vibration reduction effect from the track bed to tunnel wall in straight track compared to that in curved track.

Figure 18 shows that the vibration reduction effects are better in straight track than in curved track for most of frequency ranges. Figure 19 shows that LEST reduces the overall vibration levels by about $10.52 \mathrm{~dB}$ in straight track and $9.35 \mathrm{~dB}$ in curved track at bottom of the tunnel wall. The vibration reduction in straight track is $1.17 \mathrm{~dB}$ greater than that in curved track. Similarly, at point on the tunnel wall at $1.5 \mathrm{~m}$ height, vibration reduction of straight track is $9.60 \mathrm{~dB}$, which is greater than that in curved track. 


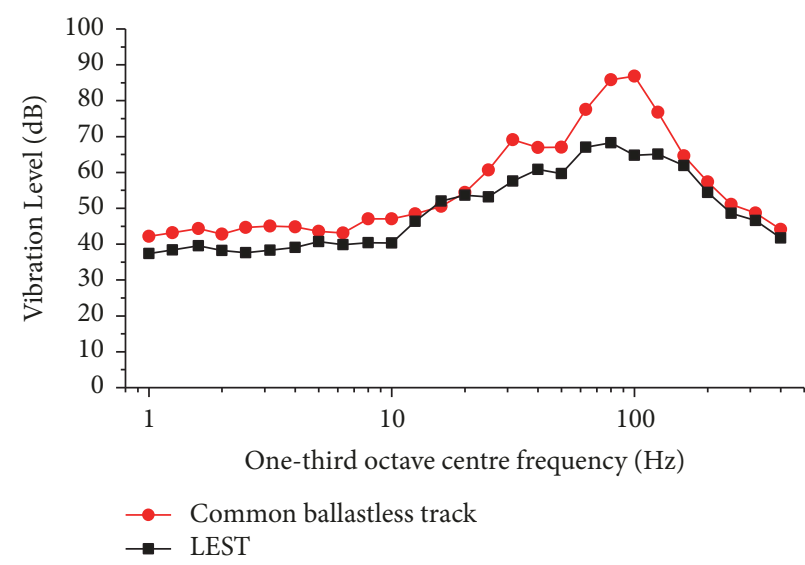

(a) Bottom of the tunnel wall

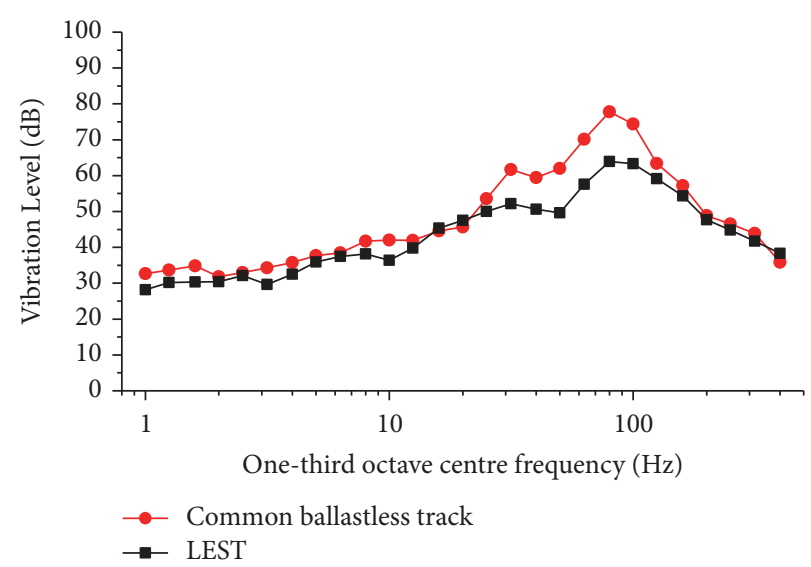

(b) Point on the tunnel wall at $1.5 \mathrm{~m}$ height

FIGURE 16: One-third octave curves of the tunnel wall vibration levels in curved track.

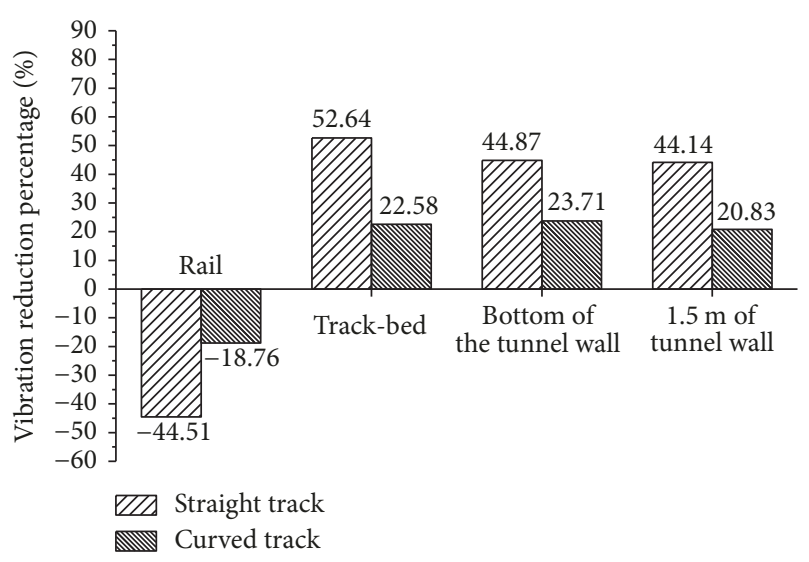

FIGURE 17: Comparison of acceleration reduction.

Under this experiment condition, the train speed of straight track $(76.5 \mathrm{~km} / \mathrm{h})$ is higher than that of curved track $(56.6 \mathrm{~km} / \mathrm{h})$. For common ballastless track, the overall vibration levels at points on the tunnel wall at $1.5 \mathrm{~m}$ height are $79.88 \mathrm{~dB}$ in straight track and $79.21 \mathrm{~dB}$ in curved track, which demonstrates that the vibration in straight track is higher than that in curved track due to a higher train speed. After setting LEST, it is surprising to note that the overall vibration level in straight track is $70.28 \mathrm{~dB}$, which is slightly lower than the $70.77 \mathrm{~dB}$ in curved track. That is to say, the presence of LEST leads to a lower vibration in straight track at a higher train speed, indicating a better vibration reduction effect of LEST on straight track. If the train speed in curved track increases, the vibration of LEST in curved track is certain to increase, due to complex wheel-rail interaction $[24,25]$. In that case, the overall vibration level in curved track would be much larger than that in straight track.

In summary, the vibration control effects of LEST in straight track are more effective than those in curved track in both time and frequency domains.

\section{Conclusions}

Experiments can help with effectively evaluating the vibration control effects of LEST. In this study, continuous dynamic tests were conducted on the sections of Beijing Subway Line 15 with common ballastless track and LEST during peak transit hours. The test results were analyzed and led to the following conclusions.

The application of LEST slightly increases the wheelrail vertical forces and vertical rail displacements, but this increase does not affect the operational safety of subway.

Applying LEST to straight track can reduce the vibration acceleration by $44.87 \%$ and $44.14 \%$ at bottom of the tunnel wall and point on the tunnel wall at $1.5 \mathrm{~m}$ height, respectively. The overall vibration levels are reduced by $10.52 \mathrm{~dB}, 9.60 \mathrm{~dB}$, and $8.84 \mathrm{~dB}$ at bottom of the tunnel wall, point on the tunnel wall at $1.5 \mathrm{~m}$ height, and ground, respectively.

Applying LEST to curved track can reduce the vibration acceleration by $23.71 \%$ and $20.83 \%$ at bottom of the tunnel wall and point on the tunnel wall at $1.5 \mathrm{~m}$ height, respectively. The overall vibration levels are reduced by $9.35 \mathrm{~dB}$ at bottom of the tunnel wall and by $8.44 \mathrm{~dB}$ at point on the tunnel wall at $1.5 \mathrm{~m}$ height.

The operating frequency of LEST is above $40 \mathrm{~Hz}$. The vibration reduction is greater in straight track than in curved track, which indicates that a better overall vibration reduction effect is achieved in straight track of the line.

These results indicate that LEST does generate a positive effect on vibration mitigation, but this effect may decrease with time. Based on field experience, the long-term performance of the elastic cushion material should be closely monitored for its crucial function of the vibration control. In addition, discreet examination of the service status of LEST during subway maintenance is necessary.

\section{Conflicts of Interest}

The authors declare that they have no conflicts of interest regarding the publication of this paper. 


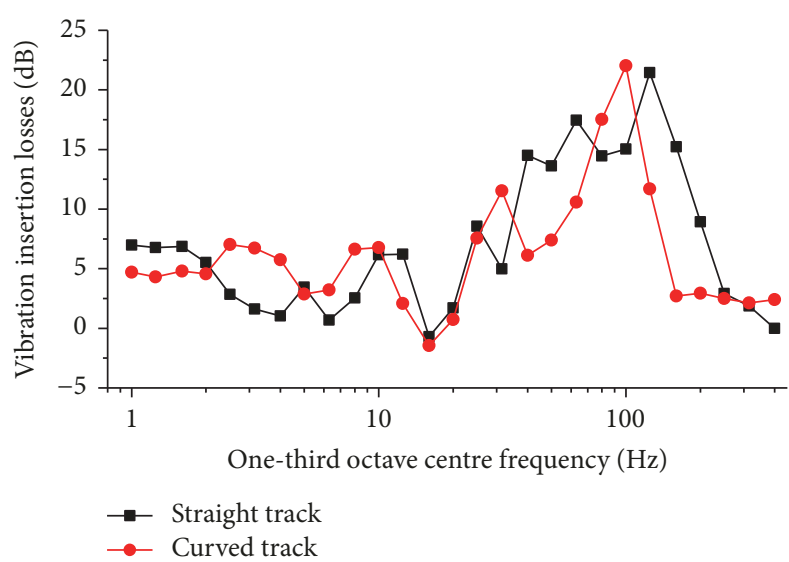

(a) Bottom of the tunnel wall

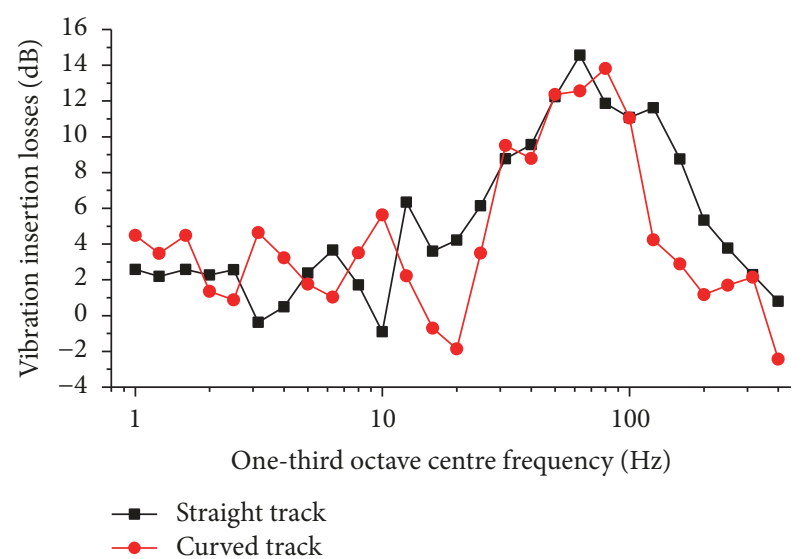

(b) Point on the tunnel wall at $1.5 \mathrm{~m}$ height

Figure 18: Insertion loss of vibration levels at the tunnel wall.

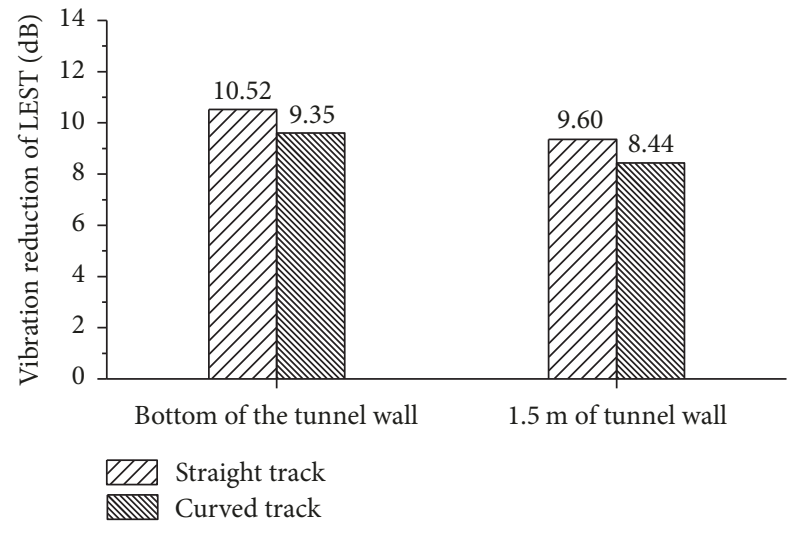

FIGURE 19: Comparison of overall vibration level reductions.

\section{Acknowledgments}

This research is sponsored by the National Natural Science Foundation of China (nos. 51578053 and 51778050), the Science and Technology Project of China Railway Corporation (2017G002-H), and the Joint Funds of Beijing Natural Science Foundation Committee and Beijing Academy of Science and Technology (no. L150003), whose supports are gratefully acknowledged.

\section{References}

[1] C. Zhao, P. Wang, X. Sheng, and D. Meng, "Theoretical simulation and experimental investigation of a rail damper to minimize short-pitch rail corrugation," Mathematical Problems in Engineering, vol. 2017, Article ID 2359404, 2017.

[2] K. W. Ngai and C. F. Ng, "Structure-borne noise and vibration of concrete box structure and rail viaduct," Journal of Sound and Vibration, vol. 255, no. 2, pp. 281-297, 2002.

[3] S. Gupta, W. F. Liu, G. Degrande, G. Lombaert, and W. N. Liu, "Prediction of vibrations induced by underground railway traffic in Beijing," Journal of Sound and Vibration, vol. 310, no. 3, pp. 608-630, 2008.
[4] C. K. Hui and C. F. Ng, "The effects of floating slab bending resonances on the vibration isolation of rail viaduct," Applied Acoustics, vol. 70, no. 6, pp. 830-844, 2009.

[5] S. Miwa, T. Hayashida, and M. Kawakubo, "Empirical study on train-induced vibration reduction with a floating railway track structure," Journal of Architecture \& Planning, vol. 64, no. 526, pp. 9-16, 1999.

[6] J. H. Kim and S. H. Youn, "The review of floating slab tracks for vibration reduction of railway station," Journal of Korean Society of Environmental Engineers, vol. 30, no. 6, pp. 581-586, 2008.

[7] M. F. M. Hussein and H. E. M. Hunt, "An insertion loss model for evaluating the performance of floating-slab track for underground railway tunnels," in Proceedings of the 10th International Congress on Sound and Vibration, pp. 1-8, Stockholm, Sweden, 2003.

[8] P. A. Costa, R. Calçada, and A. Silva Cardoso, "Ballast mats for the reduction of railway traffic vibrations. Numerical study," Soil Dynamics and Earthquake Engineering, vol. 42, pp. 137-150, 2012.

[9] T. Xin and L. Gao, "Reducing slab track vibration into bridge using elastic materials in high speed railway," Journal of Sound \& Vibration, vol. 330, no. 10, pp. 2237-2248, 2011.

[10] Q. Xu, X. Chen, B. Yan, and W. Guo, "Study on vibration reduction slab track and adjacent transition section in highspeed railway tunnel," Journal of Vibroengineering, vol. 17, no. 2, pp. 905-916, 2015.

[11] H. Xia, Y. S. Deng, and C. Y. Xia, "Dynamic analysis of coupled train-ladder track-elevated bridge system," Structural Engineering \& Mechanics, vol. 47, no. 47, pp. 661-678, 2013.

[12] C. Hanson, D. Towers, and L. Meister, Transit noise and vibration impact assessment, Federal Transit Administration, Washington DC, USA, 2006.

[13] R. Cui, L. Gao, X. Cai, and B. Hou, "Vibration and noise reduction properties of different damped rails in high-speed railway," Noise Control Engineering Journal, vol. 62, no. 4, pp. 176-185, 2014.

[14] S. Lakušić, M. Ahac, and I. Haladin, "Experimental investigation of railway track with under sleeper pad," in Proceedings of the in 10th Slovenian Road and Transportation Congress, pp. 386-393, Ljubljana, Slovenije, 2010. 
[15] C. Zhao, P. Wang, and M. Xing, "Research on the matching of fastener stiffness based on wheel-rail contact mechanism for prevention of rail corrugation," Mathematical Problems in Engineering, vol. 2017, Article ID 6748160, 2017.

[16] R. J. Hosking and F. Milinazzo, "Modelling the floating ladder track response to a moving load by an infinite Bernoulli-Euler beam on periodic flexible supports," East Asian Journal on Applied Mathematics, vol. 2, no. 4, pp. 285-308, 2012.

[17] X. R. Zeng, R. W. Zheng, and D. X. Sun, "Design and application of resiliently supported long sleepers for Capital Airport Express," Urban Rapid Rail Transit, vol. 22, no. 3, pp. 43-45, 2009.

[18] Z. C. Fan, "Finite element analysis of under-rail stiffness for slab track with long elastic sleeper," Modern Urban Transit, vol. 10, no. 6, pp. 48-51, 2013.

[19] Z. Wu and X. Y. Liu, "Analysis on coupling dynamic stiffness and energy of elastic supporting long-pillow unballasted track," Journal of the China Railway Society, vol. 34, no. 2, pp. 80-85, 2012.

[20] P. Wang, H. Xu, and R. Chen, "Effect of cement asphalt mortar debonding on dynamic properties of CRTS II slab ballastless track," Advances in Materials Science and Engineering, vol. 2014, Article ID 193128, 8 pages, 2014.

[21] C. Zhao and P. Wang, "Experimental study on the vibration damping performance of rubber absorbers for ballastless tracks on viaduct," China Railway Science, vol. 34, no. 4, pp. 8-13, 2013.

[22] Organization I S. ISO 2631-1, Mechanical Vibration and ShockEvaluation of Human Exposure to Whole-Body Vibration- Part 1- General Requirements, 1997.

[23] Technical Code for Floating Slab Track (CJJ/T 191-2012), China Architecture \& Building Press, 2013.

[24] K. Y. Wang, W. M. Zhai, J. X. Liu, Q. B. Feng, and C. B. Cai, "Dynamic performances of small-radius curved track for mountain strengthened railway," Journal of Traffic Transportation Engineering, vol. 5, no. 4, pp. 15-19, 2005.

[25] Y. Q. Sun and S. Simson, "Wagon-track modelling and parametric study on rail corrugation initiation due to wheel stick-slip process on curved track," Wear, vol. 265, no. 9-10, pp. 1193-1201, 2008. 


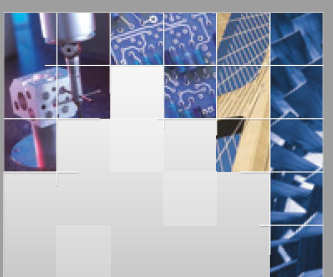

\section{Enfincering}
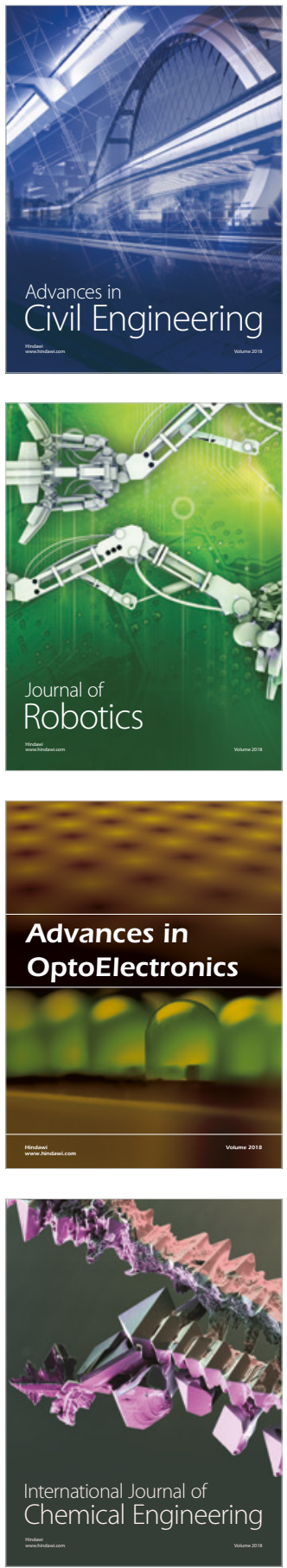

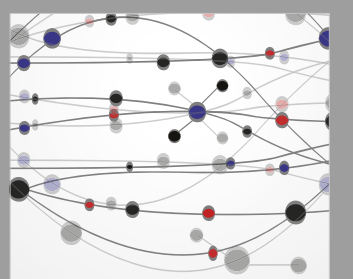

\section{Rotating \\ Machinery}

The Scientific World Journal

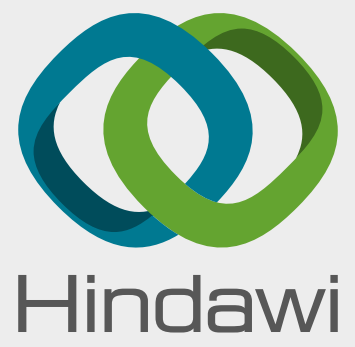

Submit your manuscripts at

www.hindawi.com
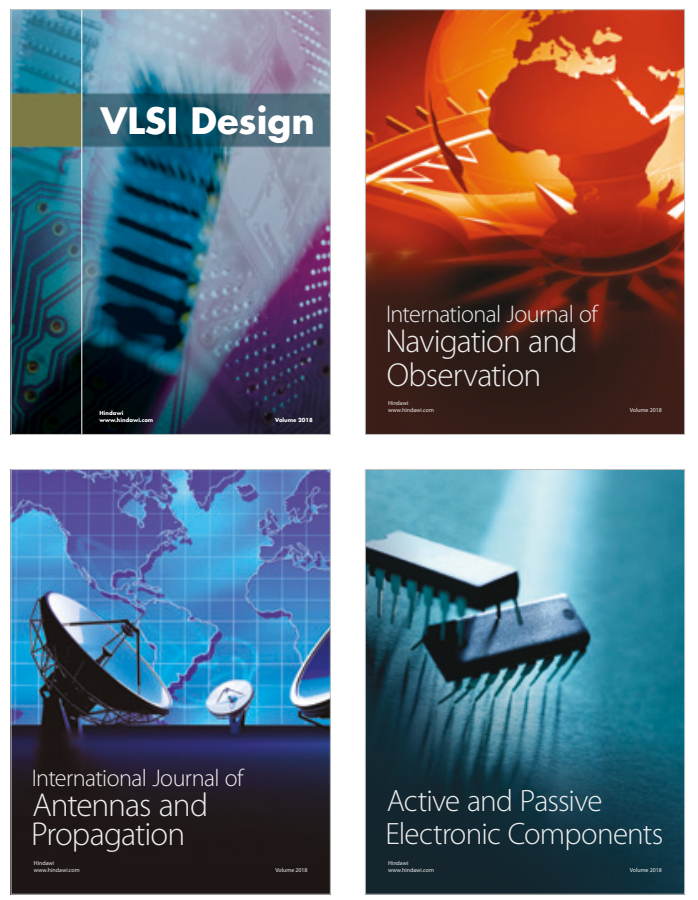
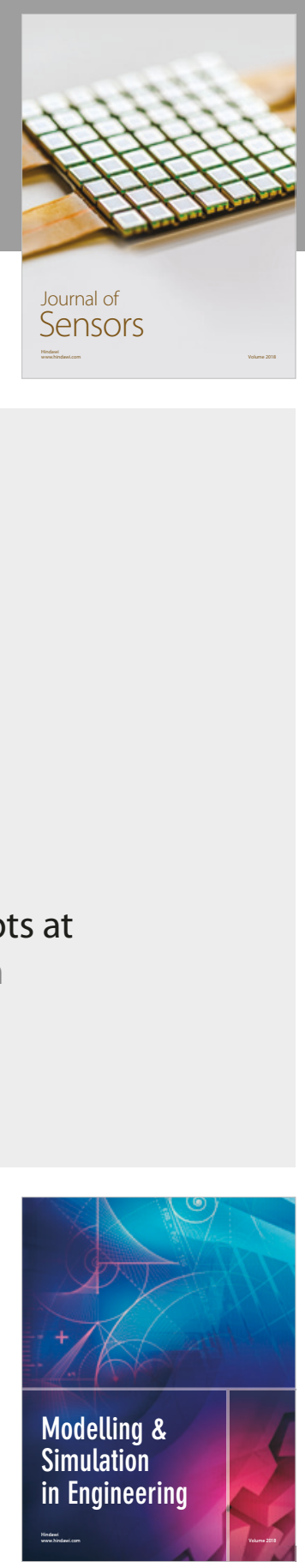

\section{Advances \\ Multimedia}
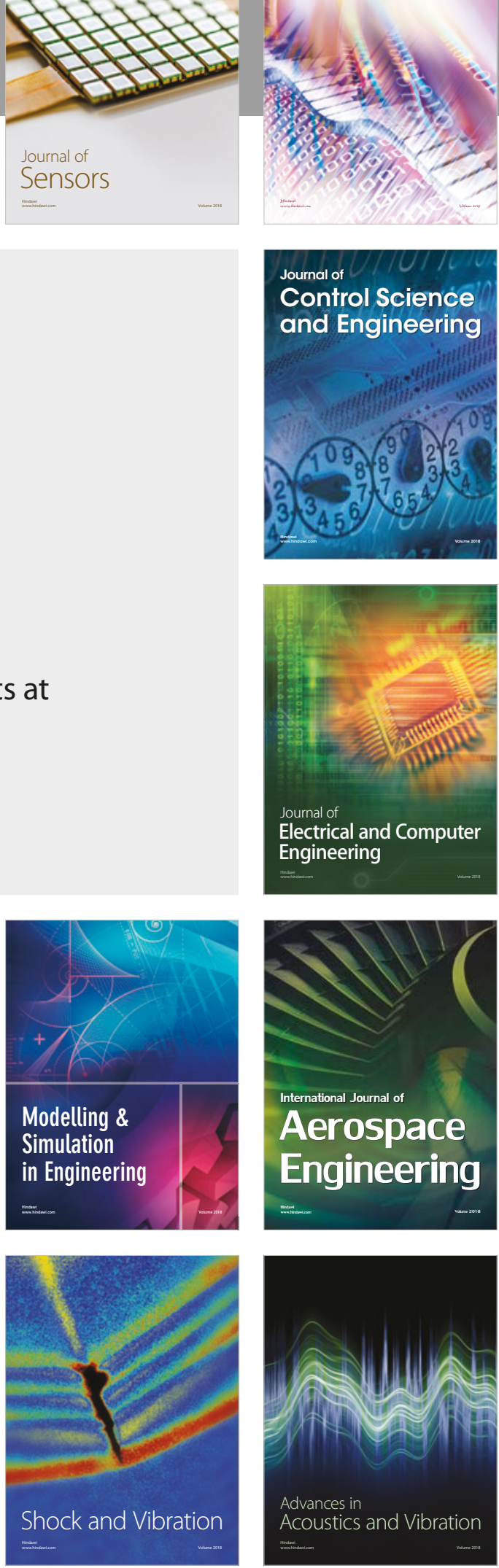